\title{
DOSIS AL FETO EN RADIODIAGNOSTICO
}

Mauricio Vergara E., MSc

Escuela de Salud Duoc-UC

\begin{abstract}
Irradiation and its effects over fetus are discussed. Also the eventuality of termination of gestation from this cause is considered.
\end{abstract}

Key words: Ionizing radiation, Fetal radiation.

Resumen: Se discute los efectos de la irradiación al feto y sus consecuencias, según dosis recibida, considerando la eventual suspensión de embarazo por esta causa.

Palabras claves: Irradiación, Radiación fetal.

\section{Introducción}

Un tema relevante en radiodiagnóstico y medicina en general; resulta ser el de una paciente mujer sometida a un estudio radiológico y en quien posteriormente, se constata que estaba embarazada. Dependiendo del tipo de estudio, es probable que el feto absorbiera una dosis por radiación fotónica y las preguntas planteadas son respecto a si esta dosis, ¿Conlleva un riesgo de malformaciones? ¿Procede indicar interrupción del embarazo?

\section{Riesgo y evidencias}

El período del embarazo más sensible a daños al feto por irradiación es entre 2 a 15 semanas después de la fecundación. Experimentos en animales sugieren que una dosis en el rango de 50 a 100 mGy puede ser fatal para el embrión. Observaciones en hijos de mujeres sobrevivientes al bombardeo de Hiroshima y Nagasaki demuestran que la malformación más frecuente es microcefalia. En la última mitad del periodo embrionario, desde las 8 a 15 semanas, existe el riesgo de déficit mental para dosis al feto cercana a los $100 \mathrm{mGy}$.

En 1977, el NCRP Report 54 recomendó, conservadoramente, que: «el riesgo de anormalidad

Vergara M. Dosis al feto en radiodiagnóstico. Rev Chil Radiol 2005; 11: 30-31.

Correspondencia: Mauricio Vergara E.

mvergarae@hotmail.com•Teléfono 3351266 no es relevante para dosis inferiores a 50 mGy y el riesgo de malformaciones sólo aumenta sustancialmente para dosis superiores a los 150 mGy.

Ahora bien, ¿Es posible en radiodiagnóstico impartir a un feto, cuya existencia no es conocida, una dosis de varias decenas de mGy? La respuesta es No y Si. En la Tabla I se muestran dosis máximas al feto en diversos estudios radiológicos ${ }^{(1)}$. De ella se concluye que la dosis al feto en radiodiagnóstico es muy inferior a la recomendación del NCRP. En otras palabras, los estudios de radiología convencional no representan riesgo para el feto. Esto corresponde al No de nuestra respuesta. El Sí ocurre en estudios abdominales de tomografía computada (TC) y, en radiología convencional, cuando la paciente es sometida a múltiples exposiciones, tanto por indicación médica como por errores técnicos hecho que representa la situación más grave desde la perspectiva del radiólogo.

Tabla I. Dosis estimada al Feto (Parry y col. Radiographics, 1999).

Estudio

Dosis (mGy)

Gastrointestinal superior 1

Colecistografía 1

Columna lumbar 4

Pelvis 2

Cadera y fémur 3

Pielografía retrógada 6

Enema baritado 10

Abdomen 3

TC abdomen 30 
EI ACR (1998) «sugiere considerar intervenir el embarazo; en presencia de otros riesgos; «Cuando la irradiación al feto se produjo en las primeras 8 semanas y la dosis al feto supera los 50 mGy». Es importante observar la cuidadosa redacción de la frase anterior: «maybe consider termination (in presence of other risks)». En modo alguno el aborto es una indicación terminante.

Independiente de la posición extrema del estudio abdominal con TC, en referencia a dosis al feto, es importante insistir que ellos son, en general, de mucho mayor riesgo para el paciente. Varios autores han estimado que los estudios con TC acumulan cerca del $60 \%$ de las dosis total a pacientes sometidos a estudios de imágenes por intermedio de radiaciones fotónicas, y sólo representan menos del $5 \%$ del número total de este tipo de estudios ( $\mathrm{Rx}, \mathrm{TC}$, medicina nuclear). EI factor técnico de la TC de mayor impacto en la dosis es la corriente de tubo, y este es el parámetro de máxima arbitrariedad seleccionado por el operador de un tomografo ${ }^{(3,4)}$. Schek y col. ${ }^{(3)}$ reporta un rango de 150 a $240 \mathrm{~mA}$, para cortes de $5 \mathrm{~mm}$ y $1 \mathrm{~s}$ de rotación, en estudios de abdomen adultos en seis centros radiológicos académicos de Alemania. Esto representa un rango de dosis al paciente de 7 a 21 mGy por corte helicoidal de $360^{\circ}$. El mismo autor registró un rango de 37 a $200 \mathrm{~mA}$, en iguales condiciones a las previas, para estudios de abdomen pediátricos, con un rango correspondiente en la dosis de 3 a $21 \mathrm{mGy}$ por corte helicoidal de $360^{\circ}$.

El reporte de Hall et al., en el British Medical Journal(5) del 2004, confirma que niños menores de 18 meses, sometidos a radioterapia cerebral, con una dosis media de $100 \mathrm{mG}$, mostraron déficit intelectual significativo a los 19 años de edad. Esta condición se compara con la observación de que la dosis al cerebro, en niños menores de dos años, durante una TC cerebral, es de aproximadamente
120 mGy. Estos antecedentes, técnicos y clínicos, y la rápida extensión en la demanda de estudios de TC en la rutina médica, han generado importantes iniciativas, tanto en EE.UU. como Europa, para cuantificar la dosis al paciente, optimizar la corriente de tubo y normalizar los parámetros de adquisición de imágenes.

\section{Conclusiones}

Los exámenes de radiodiagnóstico, apropiadamente ejecutados, son seguros para el paciente en general y el feto. Solamente errores del operador tales como repeticiones y sobreindicación en mujeres embarazadas implican un riesgo para el feto, lo cual debe evaluarse caso a caso. Para el paciente de radiodiagnóstico, y especialmente mujeres embarazadas y niños, el problema de mayor riesgo por irradiación se presenta en los estudios de TC.

\section{Bibliografía}

1. Parry RA, Glaze SA, Archer BR. The AAPM/RSNA physics tutorial for residents: Typical patient radiation doses en diagnostic radiology. Radiographics 1999; 19: 1289.

2. Golding SJ, Shrimpton PC. Radiation dose in CT: Are we meeting the challenge? $\mathrm{Br} J$ Radiol 2002; 75: 1-4.

3. Sheck RJ, Coppenrath EM, Kellner MW et al. Radiation dose and image quality in spiral computed tomography: Multicentre evaluation at six institutions. Br J Radiol 1998; 71: 734-744.

4. Vergara M, Castro M, Matas J, Arias M, Martínez G, Rosales J. Reducción de dosis al paciente en TC: Un estudio de resultados en la práctica clínica. Rev Chil Radiol 2003; 9: 29-32.

5. Hall P, Adami HO, Trichophoulos D et al. Effect of low doses of ionizing radiation in infancy on cognitive function in adulthood: Swedish population based cohort study. BMJ 2004; 328: 19. 